\title{
Food liking, food wanting, and sensory-specific satiety
}

Citation for published version (APA):

Havermans, R. C., Janssen, T., Giesen, J. C. A. H., Roefs, A. J., \& Jansen, A. T. M. (2009). Food liking, food wanting, and sensory-specific satiety. Appetite, 52(1), 222-225.

https://doi.org/10.1016/j.appet.2008.09.020

Document status and date:

Published: 01/01/2009

DOI:

10.1016/j.appet.2008.09.020

Document Version:

Publisher's PDF, also known as Version of record

Document license:

Taverne

Please check the document version of this publication:

- A submitted manuscript is the version of the article upon submission and before peer-review. There can be important differences between the submitted version and the official published version of record.

People interested in the research are advised to contact the author for the final version of the publication, or visit the DOI to the publisher's website.

- The final author version and the galley proof are versions of the publication after peer review.

- The final published version features the final layout of the paper including the volume, issue and page numbers.

Link to publication

\footnotetext{
General rights rights.

- You may freely distribute the URL identifying the publication in the public portal. please follow below link for the End User Agreement:

www.umlib.nl/taverne-license

Take down policy

If you believe that this document breaches copyright please contact us at:

repository@maastrichtuniversity.nl

providing details and we will investigate your claim.
}

Copyright and moral rights for the publications made accessible in the public portal are retained by the authors and/or other copyright owners and it is a condition of accessing publications that users recognise and abide by the legal requirements associated with these

- Users may download and print one copy of any publication from the public portal for the purpose of private study or research.

- You may not further distribute the material or use it for any profit-making activity or commercial gain

If the publication is distributed under the terms of Article $25 \mathrm{fa}$ of the Dutch Copyright Act, indicated by the "Taverne" license above, 
Research report

\title{
Food liking, food wanting, and sensory-specific satiety
}

\author{
Remco C. Havermans*, Tim Janssen, Janneke C.A.H. Giesen, Anne Roefs, Anita Jansen \\ Maastricht University, Maastricht, The Netherlands
}

\section{A R T I C L E I N F O}

Article history:

Received 27 August 2008

Received in revised form 28 September 2008

Accepted 30 September 2008

\section{Keywords:}

Liking

Sensory-specific satiety

Wanting

\begin{abstract}
A B S T R A C T
Sensory-specific satiety refers to a temporary decline in pleasure derived from consuming a certain food in comparison to other unconsumed foods. It has been argued that such a reduction may not be limited to food liking but extends to food wanting as well. Animal research suggests that sensory-specific satiety reflects a reduction in both food liking and food wanting and in the present study it was investigated whether this also holds true for humans. Participants had to consume a certain amount of chocolate milk and afterwards approximately half of the participants played a game to obtain more chocolate milk, whereas the other half played a game to obtain crisps. Participants showed a decline in subjective liking of taste and smell of the chocolate milk in comparison to crisps. Furthermore, they showed less motivation (i.e. wanting) to obtain more chocolate milk. It is concluded that sensory-specific satiety in humans reflects a decrease in both food liking and food wanting.
\end{abstract}

(C) 2008 Elsevier Ltd. All rights reserved.
Berridge (1996, 2007) argues that when examining the role of food reward in eating behaviour one has to differentiate between food liking and food wanting, with 'liking' roughly referring to palatability (i.e. the pleasure derived from eating a given food) and 'wanting' referring to appetite (i.e. the disposition to eat). Within animal research, food wanting is typically measured as instrumental behaviour to obtain food reinforcement; whereas food liking is assessed by observing facial taste reactivity patterns (see Berridge \& Robinson, 1998). According to Berridge, different neural substrates underlie the two components of food reward. Food liking appears related to opioid and GABAergic neurotransmitter systems, whereas dopaminergic neurotransmitter systems are thought to participate in food wanting. In animals, it has been shown that it is possible to dissociate food wanting and food liking. For example, dopamine depleted rats (through 6-OHDA lesions) develop aphagia, but dopamine depletion does not affect these rats' hedonic taste reactivity (see Berridge \& Robinson, 1998).

In humans too, it appears that one can dissociate food liking from food wanting. Finlayson, King, and Blundell (2007a) asked their participants to indicate on a line scale how pleasant it would be to experience a mouthful of a specific food, in order to assess food liking. Further, they adopted a forced choice methodology to assess food wanting. With this methodology participants repeatedly had to choose between two food items receiving the instruction to select the food they would most want to eat now. Finlayson and colleagues measured food liking and wanting before

\footnotetext{
* Corresponding author.

E-mail address: r.havermans@psychology.unimaas.nl (R.C. Havermans).
}

and after consumption of a meal and found that changes in food liking and wanting due to meal consumption did not always match. When hungry, participants wanted high-fat savoury foods over low-fat savoury foods with no difference in liking, and liked highfat sweet foods over low-fat sweet foods with no difference in wanting. When satiated, this pattern of results was reversed. In a more recent study, Finlayson, King, and Blundell (2008), however, failed to replicate these results. Changes in liking after meal consumption could not be fully dissociated from changes in wanting. Finlayson and colleagues thus concluded that their forced choice methodology may well assess elements of both food wanting and liking.

Perhaps a more promising approach to measuring food wanting concerns tasks in which the participant has to perform a certain instrumental response to obtain food reinforcement (see also Mela, 2006). Such a task was employed by Epstein, Truesdale, Wojcik, Paluch, and Raynor (2003). Participants had to perform a game in which they could work for points that could be traded for snack food. They had to pull a joystick in order to obtain these points. Not every response was reinforced though and throughout the task the response requirement for further snack points was regularly increased. Participants could stop working for food points whenever they wished. It was found that food deprived participants worked longer (and thus much harder) to obtain snack food than satiated participants did. Food deprivation, however, did not affect subjective ratings of food liking.

Despite the fact that food liking and food wanting can be dissociated, Berridge (1996) argues that many manipulations of food reward alter food liking and wanting together. One such manipulation concerns sensory-specific satiety, a decline in 
pleasantness derived from consuming a food with prior exposure or consumption of that specific food (Rolls, 1986). Berridge (1991) found that rats show a reduction in hedonic taste reactivity to a sucrose solution or milk after having been pre-fed with either the sucrose solution or milk. Balleine and Dickinson (1998: Experiment 1) showed in rats, that sensory-specific satiety may also affect the motivation to obtain a certain food reward. Rats first learned two distinct instrumental responses, with each response rendering a specific food reward: a salt- or lemon-flavoured polycose solution. The rats received a subsequent extinction test in which both responses were no longer reinforced. Just prior to the extinction test, however, the rats were pre-fed with one of the two flavours. At test, all rats predominantly worked to obtain the food reinforcer different from the food they had consumed just prior to the test. In other words, sensory-specific satiety not only is reflected by a reduction in liking but also by a reduction in wanting as well, at least in rats. Mela (2001) has suggested that in humans too sensory-specific satiety is likely to be reflected by a reduction in both food liking and food wanting (see also Brunstrom \& Mitchell, 2006). However, to our knowledge, this assumption has not been tested directly. Therefore, in the present study, we examined if sensory-specific satiety in humans is reflected by a reduction in liking of a given test food, and also by decreased wanting of that particular food.

\section{Method}

\section{Participants}

A total of 55 participants ( 48 female, 7 male) were recruited among the undergraduate student population of Maastricht University. Participants' characteristics are shown in Table 1. A local ethics committee reviewed and approved the present study. All participants were informed beforehand of the experimental procedure (orally and in writing) and signed a consent form. Participants were aware that participation involved the repeated tasting of chocolate milk and crisps, but they were not informed of the precise research hypothesis until after their participation.

\section{Procedure and design}

Participants were tested individually in a quiet research laboratory. All participants were instructed not to eat or drink anything (except water) $2 \mathrm{~h}$ prior to their participation. Experimental sessions were conducted during weekdays between noon and 4 p.m. On arrival, the participant was seated and first received a small cup containing $20 \mathrm{ml}$ chocolate milk (Chocomel, Friesland Foods, Veenendaal, the Netherlands) and a single paprika flavoured crisp (Lay's, Smiths Food Group, Maarssen, the Netherlands) to taste and evaluate. The participant had to indicate momentary perceived pleasantness of taste and smell of each food item on a continuous $100-\mathrm{mm}$ line scale ranging from 0 (not at all pleasant)

Table 1

Size, mean age, mean body mass index $\left(\mathrm{BMI}, \mathrm{kg} / \mathrm{m}^{2}\right)$, mean hunger and thirst ratings per group and for the total sample of participants.

\begin{tabular}{llll}
\hline & \multicolumn{2}{l}{ Group } & Total \\
\cline { 2 - 3 } & CHOC & CRISP & \\
\hline$N$ & 28 & 27 & 55 \\
Age & $21.6(5.3)$ & $21.1(3.2)$ & $21.4(4.4)$ \\
BMI & $22.25(2.58)$ & $23.75(2.65)$ & $22.99(2.70)$ \\
Hunger & $37.14(25.71)$ & $49.52(21.57)$ & $43.22(24.36)$ \\
Thirst & $37.39(19.78)$ & $35.70(20.68)$ & $36.56(20.05)$ \\
\hline
\end{tabular}

Note: Values enclosed in parentheses represent S.D. to 100 (very pleasant). The participant was allowed to taste and evaluate the chocolate milk and crisp in whatever order s/he preferred, but s/he did receive the explicit instruction to first smell each item by holding it right under the nose and that with the subsequent evaluation of taste s/he would have to fully consume each item.

Next, each participant received $250 \mathrm{ml}$ of chocolate milk to consume. After the consumption of the chocolate milk, the participants received a second tasting of the chocolate milk and crisps. Again, they had to evaluate the taste and smell of each food item. We used chocolate milk and crisps so that the two items would be generally well liked, but have a different taste, odour, and texture to minimize potential generalization of sensory-specific satiety from the chocolate milk to the crisps (Guinard \& Brun, 1998).

Next, the participants were randomly assigned to one of two groups: chocolate milk (CHOC; $n=28$ ) or crisps (CRISP; $n=27$ ). Both groups then indicated their momentary degree of hunger and thirst on separate $100-\mathrm{mm}$ line scales ranging from 0 (no hunger/ thirst at all) to 100 (very hungry/thirsty). Hunger and thirst were measured as these have been found to affect food wanting. For example, the motivation to obtain snack foods (i.e. wanting) can be stronger when feeling hungry (Epstein et al., 2003).

Participants had to play a computer game comprising a series of choices between working for either chocolate milk (group $\mathrm{CHOC}$ ) or crisps (group CRISP) and the option to stop playing. After randomly determining whether the participant would have to play for chocolate milk or crisps, the participant received the following instruction (translated from Dutch) on screen:

"In this game, you may collect points by pressing the [left/right] mouse key. When pressing this key, you may earn one point for [crisps/chocolate milk]. When pressing the other mouse key, the game will stop and you will receive 10 grams of [crisps/ chocolate milk] for each point. Pay attention! Not every [left/ right] key press will render a point. Throughout the task it will become harder to obtain further points."

Participants in group $\mathrm{CHOC}$ could trade their points for chocolate milk. With each choice (play or stop), a picture of a glass of chocolate milk and a picture of a sign reading STOP were displayed at the left and right centre of a computer screen. By clicking on the corresponding left or right mouse key, participants indicated to play for either chocolate milk or to stop playing. The position of the two pictures (left or right) was determined randomly for each separate participant. Upon selecting chocolate milk the participant received immediate feedback whether s/he had earned an additional point or not. For each of the five points, each participant had to choose chocolate milk four times to earn a single point, a fixed ratio reinforcement schedule of 4 (FR-4). For every next 5 points, the response requirement (i.e. the reinforcement ratio) was doubled. Participants could earn a maximum total of 25 points ( $250 \mathrm{~g}$ of chocolate milk). In this case the participant would have to click the same mouse key 320 times to obtain the 5 points for the final reinforcer (FR-64). Participants could, however, decide to stop playing before obtaining the maximum 25 points. The total number of points obtained would then be displayed on screen and the experimenter would serve the participant a cup of chocolate milk corresponding to the number of points. Participants in group CRISP had to play the same game, but they earned points for crisps, not chocolate milk, with each point corresponding to $10 \mathrm{~g}$ of crisps.

After the consumption of either the chocolate milk or the crisps, the participant was thanked and debriefed, and received a $€ 5$ monetary voucher or course credit for compensation. 
Table 2

The mean pleasantness ratings of the taste and smell of the chocolate milk and crisps before (pre) and after (post) the consumption of $250 \mathrm{ml}$ of chocolate milk.

\begin{tabular}{llllll}
\hline & \multicolumn{2}{l}{ Chocolate } & & & \multicolumn{2}{l}{ Crisps } \\
\cline { 2 - 3 } \cline { 5 - 6 } & Taste & Smell & & Taste & Smell \\
\hline Pre & 60.50 & 68.73 & 65.47 & 59.16 \\
Post & 50.55 & 49.24 & 67.47 & 64.06 \\
\hline
\end{tabular}

\section{Results}

Table 2 displays the mean pleasantness ratings of the taste and smell of the chocolate milk and crisps before and after the consumption of the $250 \mathrm{ml}$ of chocolate milk. Analyses of the initial pleasantness ratings of the crisps and chocolate milk revealed that participants rated the taste of these items as equally pleasant, $M$ difference $=4.93, t(54)=1.54, p=.13$. However, the participants rated the smell of the chocolate milk as significantly more pleasant than the smell of the crisps, $M$ difference $=9.56, t(54)=2.87$, $p=.01$.

\section{Sensory-specific satiety}

To evaluate the degree of sensory-specific satiety to the chocolate milk, contrasts were calculated between the taste ratings before and after the consumption of the chocolate milk for both the evaluation of the chocolate milk and crisps (see also Bell, Roe, \& Rolls, 2003). These contrasts served as the dependent variable in paired samples $t$-tests comparing (i) the shift in liking of the taste of chocolate milk with the shift in liking of the taste of the crisps and (ii) the shift in liking of the smell of chocolate milk with the shift in liking of the smell of the crisps. The rating of the pleasantness of chocolate milk showed a stronger decrease than the hedonic ratings of the crisps did. This was true for both the evaluation of taste $(M$ difference $=12.00, t[54]=3.99, p<.001$, Cohen's $d=.54$ ) and smell ( $M$ difference $=24.38, t[54]=7.50$, $p<.001$, Cohen's $d=1.01$ ).

\section{Food wanting}

To evaluate the degree to which the two groups of participants were motivated to work for either chocolate milk points or points for crisps, we conducted an ANOVA with Schedule (FR-4; FR-8; FR16; FR-32; FR-64) as the within-subject variable, Group (CHOC vs. CRISP) as the between-subjects variable, and responses per unit price for each schedule (i.e. the required number of responses to complete the schedule $\times$ the total number of responses during that schedule/the total amount of points obtained during that schedule $\times$ reinforcer magnitude [i.e. $10 \mathrm{~g}$; see also Epstein et al., 2003]) as the dependent variable. Unit price expresses the ratio of response cost to reinforcer gain and reflects the fact that consumption is controlled by both costs (e.g. required effort to obtain a reinforcer) and reinforcer magnitude or dose (see DeGrandpre, Bickel, Hughes, Layng, \& Badger, 1993; Hursh, 2000).

As the total number of responses of two participants ( 1 from group CHOC and 1 from group CRISP) deviated more than 3 S.D.s from the group mean, the data from these two participants were excluded from the analysis. Fig. 1 displays the mean unit price per reinforcement schedule separately for group $\mathrm{CHOC}$ and group CRISP.

Significant main effects of trial $[F(4,204)=9.22, p<.001$, $\left.\eta_{\text {partial }}^{2}=.15\right]$ and group $\left[F(1,51)=8.55, p=.005, \eta_{\text {partial }}^{2}=.14\right]$ were found. These effects were qualified by a significant trial $\times$ group interaction, $F(4,204)=3.85, p<.01, \eta_{\text {partial }}^{2}=.07$,

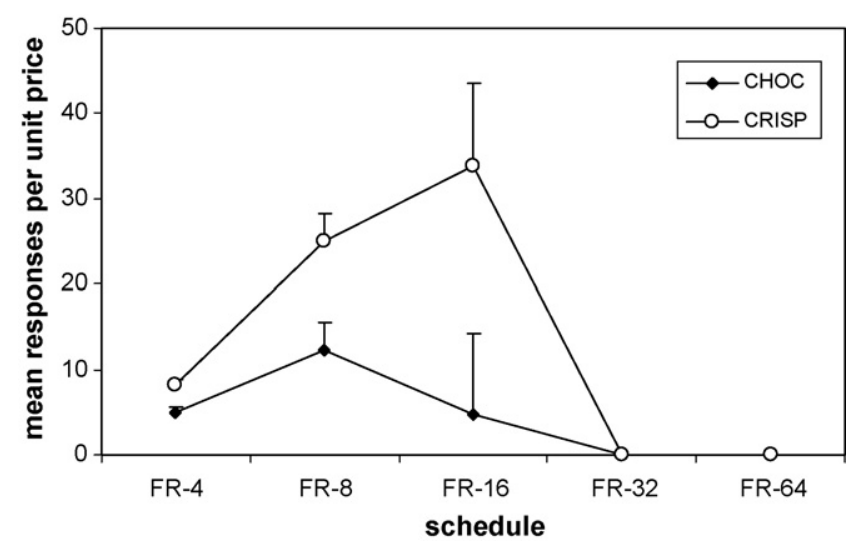

Fig. 1. Mean responses per unit price (+S.E.M.) per reinforcement schedule for each separate group (i.e. CHOC vs. CRISP).

reflecting a larger number of responses for food points by the participants in group CRISP for the first three reinforcement schedules of the task. ${ }^{1}$ Post hoc independent samples $t$-tests revealed a significant difference between groups CHOC and CRISP in mean unit price for the reinforcement schedules FR-4 $[t(51)=3.49, p=.001]$, FR-8 $[t(51)=2.83, p=.007]$, and FR-16 $[t(51)=2.14, p=.04]$.

The pattern of results suggests, in line with our hypothesis, that at least in the case of sensory-specific satiety the observed change in subjective liking is paralleled by a corresponding change in wanting. Following up on this suggestion, we determined whether subjective liking (assessed directly prior to the choice game) of the food participants had to play for during the computer game correlated with the total number of points for this food obtained during the game. If sensory-specific satiety is reflected by both a decrease in food wanting and food liking then one would expect to see at least a modest positive correlation between these measures, which is what we found, $r=.42, p<.05$.

\section{Discussion}

The present study examined whether sensory-specific satiety leads to a reduction in both food liking and food wanting. Subjective pleasantness ratings revealed a clear sensory-specific satiety effect for the chocolate milk and this effect corresponded with less motivation (i.e. wanting) to obtain points for chocolate milk than to obtain points for crisps. This pattern of results implies that in humans, as appears to be the case in rats, sensory-specific satiety is reflected by a reduction in both food liking and food wanting. In line with the present findings, Brunstrom and Mitchell (2006: Experiment 2) showed a relative decrease in subjective ratings of both the desire to eat and ratings of pleasantness with the consumption of cakes. Note that the apparent correspondence between measures of food liking and wanting with sensoryspecific satiety should not be interpreted as refuting the distinction between liking and wanting. Indeed, despite the positive correlation between the two measures it is possible that satiety changes food wanting to a greater degree than it does liking (or vice versa).

\footnotetext{
${ }^{1}$ No difference in thirst as indicated just prior to working for food points between the two groups was found, $t(51)=.68, p=.50$, but despite random allocation to the groups $\mathrm{CHOC}$ and CRISP a significant difference in hunger ratings was found between the groups, $t(51)=2.09, p=.04$. Furthermore, BMI also significantly differed between groups $\mathrm{CHOC}$ and CRISP, $t(51)=2.39, p=.02$. Therefore, the analysis was repeated with covariates hunger and BMI. This analysis did not reveal any effects of hunger and BMI and thus these covariates were left out of the final analysis.
} 
Unfortunately, the use of two very different ways to measure liking and wanting does not permit us to assess this possibility in the present study.

Sensory-specific satiety is typically described in terms of a relative shift in affect, but it seems clear that this also includes a shift in the motivation to eat and/or drink. On the basis of the present study, though, this conclusion should be considered with some caution. First, we did not counterbalance the test food between participants; they all consumed chocolate milk. Theoretically there is no reason to assume that sensory-specific satiety to chocolate milk differs in any sense from sensory-specific satiety to crisps, but in the absence of a balanced design such a potential difference cannot be ruled out. Second, we argue that the food wanting measure we used is uncontaminated by affective processes and thus assesses true wanting, yet some might disagree. Finlayson et al. (2008) point out that it is important to distinguish between explicit and implicit wanting as Berridge (2007) has argued that wanting may not be a consciously experienced motivation. To assess wanting, the participants in the present study repeatedly had to decide to obtain further points, or not. It is possible that participants factored in their momentary liking of the chocolate milk or crisps in making these deliberate decisions. But even when the effort invested by the participants to obtain these points is viewed to primarily reflect wanting, it is unlikely that this task assesses implicit wanting.

Finlayson et al. (2008) have attempted to measure both explicit and implicit wanting. They measured reaction time latency of the participants' responses during the forced choice task. The forced choice task renders a relative food preference score thought to reflect explicit food wanting, and "the speed with which one stimulus is chosen in preference to its alternative ... may relate to the implicit wanting for that food" (p. 121). Finlayson and colleagues found that the relative food preference score could not be fully dissociated from subjective food liking scores, but mean reaction times did not correlate with explicit liking and wanting measures. This, however, still does not mean that the reaction times reflected 'true' implicit wanting uncontaminated by liking. Reaction time in and of itself says very little about the implicit nature underlying the choice of a certain food item over another food item, even when participants are unaware that their reaction times are recorded.

It is clear that the development of adequate measures of food wanting and liking requires further research. This is an important endeavour as it may further our understanding of weight regulation and the aetiology of obesity in particular (Berridge, 2007; Finlayson, King, \& Blundell, 2007b; Mela, 2006). Mela has noted that obese persons do not seem to overly like the flavour of high-caloric foods when compared to the evaluations of normal-weight persons. Further, when considering hedonic ratings of food (i.e. liking), the degree of sensory-specific satiety does not vary with weight-status
(Brondel et al., 2007; Snoek, Huntjens, van Gemert, de Graaf, \& Weenen, 2004). The excessive caloric intake presumed to underlie the development of obesity then is more likely to be the result of exaggerated food wanting (see also Berridge, 2007). If true, then food wanting and food liking might dissociate within obese participants undergoing a sensory-specific satiety procedure, with food wanting being less affected by sensory-specific satiety in obese persons in comparison with normal-weight persons. As the present study did not include obese participants, further research is required to determine whether this is the case.

\section{References}

Balleine, B. W., \& Dickinson, A. (1998). The role of incentive learning in instrumental outcome revaluation by sensory-specific satiety. Animal Learning \& Behavior, 26, 46-59.

Bell, E. A., Roe, L. S., \& Rolls, B. J. (2003). Sensory-specific satiety is affected more by volume than by energy content of a liquid food. Physiology \&'Behavior, 78, 593-600.

Berridge, K. C. (1991). Modulation of taste affect by hunger, caloric satiety, and sensoryspecific satiety in the rat. Appetite, 16, 103-120.

Berridge, K. C. (1996). Food reward: brain substrates of wanting and liking. Neuroscience and Biobehavioral Reviews, 20, 1-25.

Berridge, K. C. (2007). Brain reward systems for food incentives and hedonics in normal appetite and eating disorders. In T. C. Kirkham \& S. J. Cooper (Eds.), Progress in brain research: appetite and body weight (pp. 191-216). New York: Academic Press.

Berridge, K. C., \& Robinson, T. E. (1998). What is the role of dopamine in reward: hedonic impact, reward learning, or incentive salience? Brain Research Reviews, 28 , 309-369.

Brondel, L., Romer, M., Van Wymelbeke, V., Walla, P., Jiang, T., \& Rigaud, D. (2007). Sensory-specific satiety with simple foods in humans: no influence of BMI? International Journal of Obesity, 31, 987-995.

Brunstrom, J. M., \& Mitchell, G. L. (2006). Effects of distraction on the development of satiety. British Journal of Nutrition, 96, 761-769.

DeGrandpre, R. J., Bickel, W. K., Hughes, J. R., Layng, M. P., \& Badger, G. (1993). Unit price as a useful metric in analyzing effects of reinforcer magnitude. Journal of the Experimental Analysis of Behavior, 60, 641-666.

Epstein, L. H., Truesdale, R., Wojcik, A., Paluch, R. A., \& Raynor, H. A. (2003). Effects of deprivation on hedonics and reinforcing value of food. Physiology \& Behavior, 78, 221-227.

Finlayson, G., King, N., \& Blundell, J. E. (2007a). Is it possible to dissociate 'liking' and 'wanting' for foods in humans? A novel experimental procedure. Physiology $\mathcal{E}$ Behavior, 90, 36-42.

Finlayson, G., King, N., \& Blundell, J. E. (2007b). Liking vs. wanting food: importance for human appetite control and weight regulation. Neuroscience and Biobehavioral Reviews, 31, 987-1002.

Finlayson, G., King, N., \& Blundell, J. E. (2008). The role of implicit wanting in relation to explicit liking and wanting for food: implications for appetite control. Appetite, 50 120-127.

Guinard, J. X., \& Brun, P. (1998). Sensory-specific satiety: comparison of taste and texture effects. Appetite, 31, 141-157.

Hursh, S. R. (2000). Behavioral economic concepts and methods for studying health behavior. In W. K. Bickel \& R. E. Vuchinich (Eds.), Reframing health behavior change with behavioral economics (pp. 27-62). Mahwah, NJ: Lawrence Erlbaum Associates.

Mela, D. J. (2001). Why do we like what we like? Journal of the Science of Food and Agriculture, 81(1), 10-16.

Mela, D. J. (2006). Eating for pleasure or just wanting to eat? Reconsidering sensory hedonic responses as a driver of obesity. Appetite, 47, 10-17.

Rolls, B. J. (1986). Sensory-specific satiety. Nutrition Reviews, 44, 93-101.

Snoek, H. M., Huntjens, L., van Gemert, L. J., de Graaf, C., \& Weenen, H. (2004). Sensoryspecific satiety in obese and normal-weight women. American Journal of Clinical Nutrition, 80, 823-831. 